\title{
The effects of chronic cobalt exposure on passive-avoidance performance in the adult rat
}

\author{
WENDY J. BOURG and JACK R. NATION \\ Texas A\&M University, College Station, Texas \\ and \\ DONALD E. CLARK \\ United Services Department of Agriculture, College Station, Texas
}

\begin{abstract}
Adult male rats were tested for acquisition and retention of step-down passive avoidance following exposure to either distilled water contaminated with cobalt chloride (Group Cobalt) or uncontaminated distilled water (Group Control). Exposure to $20 \mathrm{mg}$ cobalt/kg body weight per day, for 57 days, produced significantly greater step-down passive-avoidance latencies during retention testing in Group Cobalt relative to controls. Analyses of passive-avoidance-acquisition data, analgesic-tolerance test results, and body weights produced no significant group differences. Significant accumulations of cobalt were detected in blood, brain, and left testis of treated animals.
\end{abstract}

Toxic effects of cobalt (Co) have been observed in animals and humans even with low-level exposure (Anonymous, 1966). Polycythemia (Browning, 1969), goitrogenic effects (Wills, 1966), cardiomyopathy (Morin \& Daniel, 1967) and hyperglycemia (Schroeder, Nason, \& Tipton, 1967) have been reported following oral ingestion of Co. Additionally, industrial exposure to Co has occasioned respiratory (Browning, 1969) and pulmonary ailments (Young, 1979).

Of particular relevance to the present study are the neurotoxic disturbances produced by Co contamination. Various types of Co brain implants (Co rods, pellets, etc.) are known to cause epileptic seizures in many animals, including rats and monkeys (Emson \& Joseph, 1975; Hoover, Cublerson, \& Craig, 1977; Ribak, 1979). This seizure activity has been shown to be accompanied by significant reductions in the levels of selected neurotransmitters and enzymes involved in their synthetic pathways. Such depletions include a 50\% reduction in the amount of the ubiquitous inhibitory neurotransmitter GABA (gamma-aminobutyric acid) as well as glutamic acid decarboxylase (Emson \& Joseph, 1975). In addition to the effects observed with Co implants, Co injections into the substantia nigra of rats have induced decreased CNS levels of dopamine, GABA, and glutamic acid decarboxylase (Shibuya et al., 1978). Intraperitoneal injections of Co have produced depletion of dopamine (DA), norepinephrine (NE), and 5-hydroxytryptomine (5HT)

The research reported in this article was conducted under the auspices of the University Undergraduate Fellows Program at Texas A\&M University. We are grateful to Dorothy Baker and Mike Hare for their assistance in the analyses of this study, and to Scott Weigold for his invaluable moral support and technical asssistance. concentrations in various regions of the rat brain (Hasan, Ali, \& Anwar, 1980).

Despite the demonstrated neurotoxicity of Co, only a few behavioral studies have been conducted in an effort to determine the degree of functional impairment occasioned by the metal (cf. Nation, Bourgeois, Clark, \& Hare, 1983). Moreover, no investigations demonstrating the toxic effects of Co on aversively motivated behaviors have been published to date. Consequently, the present study examined the role of Co in the promotion of stress reactivity in animals using a passive-avoidance paradigm.

\section{METHOD}

\section{Subjects}

Subjects were 16 male Sprague-Dawley rats approximately 80 days old and weighing 150-200 $\mathrm{g}$ at the start of the experiment. All animals were placed on a 20 -g daily diet (Purina Lab Chow, Ralston Purina Co., St. Louis, MO), which was maintained throughout the experiment in order to produce homogenous body weights. Simultaneously, 8 randomly selected rats (Group Cobalt) began receiving $\mathrm{Co}$ in the form of cobalt chloride $\left(\mathrm{CoCl}_{2}\right)$ in distilled water, and continued to receive this solution through the final day of testing. The remaining 8 animals (Group Control) received distilled water with no added Co.

\section{Preparation of Fluid}

Co levels in the water were adjusted over the course of the experiment in order to maintain a constant $20-\mathrm{mg} \mathrm{Co} / \mathrm{kg}$ body weight exposure regimen. Since animal body weights increased as the experiment progressed, the absolute amount of Co in their water supply was similarly increased in order to maintain this exposure level. The concentra-

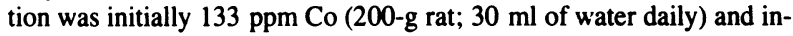
creased to a final value of $171 \mathrm{ppm} \mathrm{Co} \mathrm{(300-g} \mathrm{rat;} 35 \mathrm{ml}$ of water daily). New solutions were prepared every 3 days, and the concentration of Co in the water was analyzed by atomic absorption spectrophotometry at the end of each week to assess the accuracy of Co content.

\section{Apparatus}

Behavioral testing was conducted in a $25 \times 28 \times 31-\mathrm{cm}$ Coulborn E10-10 modular operant cage housed in a $41 \times 46 \times 56$-cm Coulborn 
E10-20 universal cubicle. This apparatus was modified to accommodate step-down passive-avoidance acquisition and retention training through addition of a $5 \times 10 \times 15$-cm wooden block. To facilitate viewing, the cubicle door was left open for the duration of each animal's session. With the cage lights on, the room lights were turned down and noise was minimized to assure that the subject would not be distracted. The chamber floor consisted of stainless-steel grid rods spaced $2 \mathrm{~cm}$ apart. The grid could be electrified by a Coulborn E13-08 grid-floor shock generator.

A hot-plate apparatus was used to test for analgesic tolerance. The apparatus consisted of a slide-warming tray (Clinical Scientific Equipment Co., Melrose Park, IL) with the temperature dial set to remain at a relatively constant $120^{\circ} \mathrm{F}$ (approximately $50^{\circ} \mathrm{C}$ ). Actual plate temperature was monitored by a Fluke $2100 \mathrm{~A}$ digital readout thermometer (Seattle, WA) and was recorded for each animal upon placement in the apparatus. A $76 \times 38 \times 89$-cm clear plastic chamber with a hinged top and an open bottom was placed on the slide-warming tray surface. A 40-W light was mounted above the apparatus. Paw-lick latencies were recorded to the nearest $.01 \mathrm{sec}$ by a Gerbrands G1280 digital electronic timer. All behavioral testing was conducted in a test room isolated from the animal holding room.

\section{Procedure}

All animals were exposed to the respective control or Co-contaminated water for 57 days prior to the beginning of acquisition training.

Acquisition training. Animals across groups were run in a counterbalanced order. Each training session lasted $30 \mathrm{~min}$. Timing for each session began when the animal was placed on the platform, with a 1.5$\mathrm{mA}$ shock continuously applied to the grids below. The platform was located in the corner of the chamber, adjacent to the back and left walls. This placement was made specifically to prevent interference by the competing thigmotactic response which occurs with a centrally placed platform (Grossen \& Kelly, 1972). The distance from the top of the platform to the grid floor was $10 \mathrm{~cm}$. Thus, animals were shocked continuously, contingent upon each descent, until returning to the platform. The number of platform descents (defined here as touching the grids with one or more paws) functioned as the dependent measure. The chamber was thoroughly washed with a soap solution following each animal's session.

Retention testing. Twenty-four $\mathrm{h}$ following acquisition training, each animal was again placed on the platform, but no shock was delivered to the grid flooring. The initial step-down latency (the amount of time the animal took to step off the platform and place all four paws onto the grid flooring) was the dependent measure for retention. If an animal failed to descend from the platform within a 5-min period, latency was recorded as $5 \mathrm{~min}$ and the animal was removed from the testing chamber. Animals were taken immediately to the home cage following this initial step-down performance.

Analgesic tolerance. Twenty-four $\mathrm{h}$ after retention testing, a hot-plate test was conducted to measure analgesic tolerance. The test was conducted according to an established procedure (Wellman, Watkins, Nation, \& Clark, 1984) whereby each animal was placed on the hot-plate surface, and latency to perform a paw-lick response to any paw was recorded to the nearest $.01 \mathrm{sec}$ as paw-lick latency (PLL). If a paw-lick response was not observed within $90 \mathrm{sec}$, the test was terminated and PLL recorded as $90 \mathrm{sec}$. Each animal was returned to the home cage immediately following this evaluation.

Table 1

Mean Daily Co Intake Over Weeks for Group Cobalt and Mean Weekly Water Consumption for Groups Cobalt and Control Week

\begin{tabular}{|c|c|c|c|c|c|c|c|c|}
\hline \multirow[b]{2}{*}{ Group } & \\
\hline & 1 & 2 & 3 & 4 & 5 & 6 & 7 & 8 \\
\hline \multicolumn{9}{|c|}{ Average Daily Co Consumption Across Weeks ( $\mathrm{mg} / \mathrm{kg}$ body weight) } \\
\hline Cobalt & 24.2 & 20.9 & 21.3 & 20.4 & 21.0 & 19.3 & 18.0 & 17.0 \\
\hline \multicolumn{9}{|c|}{ Average Weekly Water Intake (ml) } \\
\hline & 252 & 249 & 250 & 263 & 248 & 247 & 238 & 211 \\
\hline Control & 276 & 286 & 299 & 320 & 306 & 321 & 327 & 329 \\
\hline
\end{tabular}

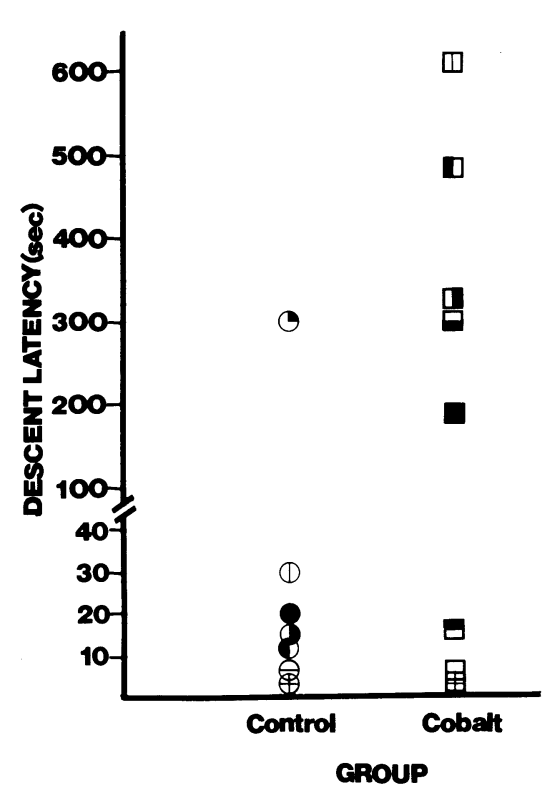

Figure 1. Individual descent latencies for Group Control and Group Cobalt during passive-avoidance-retention testing.

Biochemical analyses. Immediately after analgesic-tolerance testing was completed, all rats were sacrificed via decapitation. Blood, brain, and left-testis samples were collected and stored $\left(-60^{\circ} \mathrm{C}\right)$ until analyses. In preparation for tissue assays, samples were dried in a $120^{\circ} \mathrm{F}$-oven, then ashed overnight in a muffle furnace at $500^{\circ} \mathrm{F}$. Following the drying and ashing procedures, samples were dissolved in $1 \mathrm{ml}$ of $\mathrm{HCl}$ and 5 drops of $\mathrm{HNO}_{3}$. This mixture was quantitatively transferred to volumetric flasks and diluted to a volume of $5 \mathrm{ml}$. This solution was then analyzed for Co content (wet weight) via atomic absorption spectrophotometry, using an open flame technique (Varian Techtron, Palo Alto, CA).

\section{RESULTS}

Because of equipment failure, one animal in Group Control was discarded. None of the results reported below include data from the discarded animal.

Fluid intake. Average daily Co consumption in the treatment group was computed in order to verify the exposure regimen. Results are reported in Table 1. Actual Co consumption compared favorably with the desired $20 \mathrm{mg} / \mathrm{kg}$ regimen.

Water consumption in both Group Cobalt and Group Control, continuously monitored, is also reported in Table 1 . A 2 (treatments) $\times 8$ (weeks) repeated-measures analysis of variance performed on these data showed that across weeks water intake for Group Cobalt was less than that for Group Control $[\mathrm{F}(1,8)=68.3, \mathrm{p}<.01]$.

Body weight. All animals were weighed just prior to testing. Mean body weights were $340 \mathrm{~g}$ and $347 \mathrm{~g}$ for Groups Control and Cobalt, respectively. No significant differences were evident between the two groups $[\mathrm{t}(13)=.90, \mathrm{p}>.05]$.

Acquisition training. No significant differences between groups were observed in number of descents during acquisition training. Means for the two groups were 
5.9 and 4.2 descents for Groups Control and Cobalt, respectively. An independent sample t test performed on these data confirmed the lack of group separation $[\mathrm{t}(13)=1.5 ; \mathrm{p}>.10]$.

Retention testing. Individual latencies on the retention test are shown in Figure 1. Findings from the analysis of retention latencies indicated that Group Cobalt animals exhibited significantly longer latencies to descend completely from the platform than did their control counterparts. Mean latencies for stepping off the platform $24 \mathrm{~h}$ after acquisition were $53.6 \mathrm{sec}$ for Group Control and $237 \mathrm{sec}$ for Group Cobalt. The data were analyzed by a two-sample randomization test suggested by Good (1979). Results from this test indicated that there were significant differences between groups in descent latency. With theta set at the recommended level of .67, $p=.045$. This indicated that the probability that the treatment group would show this value, when considered against the background of all possible permutations of control and treatment values, was low and therefore unlikely to be due to chance. So, at least under the conditions of this project, animals treated with Co were less likely to descend from the platform and thus exhibited enhanced avoidance retention relative to controls.

Analgesic tolerance. No marked group differences in analgesic tolerance were indicated. Group means were $55 \mathrm{sec}$ and $46 \mathrm{sec}$ for Groups Control and Cobalt, respectively $[\mathrm{t}(13)=.84, \mathrm{p}>.05]$.

Biochemical analyses. Large group differences were observed in residue accumulations of Co in all three tissues examined (blood, brain, and left testis). These data are reported in Table 2 . Independent sample $t$ tests, performed on group means generated for each tissue type, confirmed this conclusion [blood: $\mathrm{t}(13)=5.90$, $\mathrm{p}<.001$; brain: $\mathrm{t}(13)=6.30, \mathrm{p}<.001$; testis: $\mathrm{t}(13)$ $=5.40, \mathrm{p}<.001]$.

\section{DISCUSSION}

Insofar as avoidance performance is mediated by stress-related events, the findings of this study indicate that chronic oral exposure to Co enhances emotional reactivity in rats. Though passive-avoidance-acquisition performance was unaffected, animals exposed to $20 \mathrm{mg} \mathrm{Co} / \mathrm{kg}$ body weight were less likely than controls to descend from a safe platform onto an electrified grid floor during retention testing. These differences were observed to occur coincident with significant accumulations of $\mathrm{Co}$

Table 2

Co Concentrations in Blood, Brain, and Testis of Group Cobalt and Group Control Animals

\begin{tabular}{cccc}
\hline & \multicolumn{3}{c}{ Tissue } \\
\cline { 2 - 4 } Group & Blood & Brain & Testis \\
\hline Control $(\mathrm{N}=7)$ & & & \\
Mean & .003 & .021 & .007 \\
SD & .002 & .022 & .005 \\
Cobalt $(\mathrm{N}=8)$ & & & \\
Mean & .408 & .225 & .299 \\
SD & .181 & .083 & .141 \\
\hline
\end{tabular}

in selected tissues of the treated animals. No group differences were observed in either analgesic tolerance or body weights.

The effects observed here may be due to Co-induced disturbances in neurochemistry. In this regard, the aforementioned Co-induced disruption of GABA transmission takes on added meaning (see Shibuya et al., 1978), considering that GABA bioavailability is linked to stress reactivity. But several other possible accounts of our findings must be considered. First, changes could occur at the level of the sensory receptor, such that Co-treated (Group Cobalt) animals would have experienced more intense pain than controls, and thus an exaggerated avoidance reaction would be expected for treated animals. However, results from the hot-plate test are inconsistent with this position. Specifically, Co-treated animals were equally as responsive to painful stimuli as were untreated controls. Differences in electrical resistance resulting from disparate body weights across groups also could have produced differences in reactivity. However, the lack of weight differences observed here is inconsistent with this line of reasoning.

Also recall that the results showed that Co-treated animals drank a significantly lower quantity of water relative to controls. Although no obvious indications of wasting (such as reduced body weights or malaise) were observed in this study, differential fluid intake has to be considered as a potential source of confounding. Specifically, as a result of the possible drive-inducing properties of water deprivation, it can be argued that Co-treated animals were subject to enhanced motivation by virtue of their being water-deprived. Thus the behavioral differences observed in this study could be attributed to an elevated nonspecific state of arousal rather than to the effects of Co exposure per se. However, previous studies (Young \& Black, 1977) have indicated that the state of the water-regulatory system affects only behaviors which are directly connected with that system, and not unrelated operants. Therefore the claim that water deprivation could contribute to a generalized drive state motivating increased avoidance performance in deprived animals would not appear to be very convincing.

\section{REFERENCES}

Anonymous (1966). Cobaltous salts: Revocation. Federal Register 31, 10744.

BRowning, E. (1969). Toxicity of industrial metals. London: Butterworth.

EMSON, P. C., \& JoSEPH, M. H. (1975). Neurochemical and morphological changes during the development of cobalt-induced epilepsy in the rat. Brain Research, 93, 91-110.

Good, P. I. (1979). Detection of a treatment effect when not all experimental subjects will respond to treatment. Biometrics, 35, 483-489.

Grossen, N. E., \& Kelley, M. J. (1972). Species-specific behavior and acquisition of avoidance behavior in rats. Journal of Comparative \& Physiological Psychology, 81, 307-310.

Hasan, M., Ali, S. F., \& Anwar, J. (1980). Cobalt-induced depletion of dopamine, norepinephrine, and 5-hydroxytryptamine concentrations in different regions of the rat brain. Indian Journal of Experimental Biology, 18, 1051-1052.

Hoover, D. B., Cublerson, J. L., \& Craig, C. R. (1977). Structural changes in cerebral cortex during cobalt induced epilepsy in the rat. Neuroscience Letters, 4, 275-280.

Morin, Y., \& DANIEL, P. (1967). Quebec beer-drinkers cardiomyopathy: Etiological considerations. Journal of the Canadian Medical Association, 97, 926-931.

Nation, J. R., Bourgeois, A. E., Clark, D. E., \& Hare, M. F. (1983). The effects of chronic cobalt exposure on behavior and metallothionein levels in the adult rat. Neurobehavioral Toxicology \& Teratology, 5, 9-15.

RIBAK, C. R. (1979). Inhibitory GABA-ergic nerve terminals decrease at sites of focal epilepsy. Science, 205, 211-214.

Schroeder, H. A., Nason, A. P., \& Tipton, I. H. (1967). Essential trace metals in man: Cobalt. Journal of Chronic Disease, 20, 869-890.

Shibuya, M., Fariello, R., Farley, I. J., Rice, K. G. Lloyd, K. G. \& HoRNYKEIWICZ, O. (1978). Cobalt injections into the substantia nigra of the rat: Effect on behavior and dopamine metabolism in the striatum. Experimental Neurology, 58, 486-499. 
Wellman, P., Watkins, P., Nation, J. R., \& Clark, D. (1984). Conditioned taste aversion in the adult rat induced by dietary ingestion of cadmium or cobalt. Neurotoxicology, 5, 81-90.

Wills, J. L. (1966). Goitrogens in foods. In Food Protection Committee: Toxicants Occurring Naturally in Foods. Washington, DC: National Academy of Science Publication No. 1354.
Young, G., \& BLACK, A. H. (1977). A comparison of operant licking and lever pressing in the rat. Learning \& Motivation, 8, 387-403. Young, R. S. (1979). Cobalt in biology and biochemistry. New York: Academic Press.

(Manuscript received for publication July 3, 1985.) 